\title{
Eğitim, Sağlık ve AR-GE Harcamaları ile Ekonomik Büyüme Arasındaki İlişkinin ARDL Sınır Testi ile Belirlenmesi
}

\author{
Yildırım DEMIR ${ }^{1}$
}

Öz

İnsanoğlu, yaşam standardını yükseltmek için sürekli bir çaba içerisinde olmuştur. Ancak daha sağlıklı, bilinçli ve kaliteli yaşam standartlarına ulaşmanın yolu genellikle iktisadi zaman serileri arasındaki ilişkilerin doğru bir şekilde belirlenmesi ve dolayısıyla daha iyi bir kalkınma stratejisi geliştirmesi ile mümkün olabilir. Bu amaç doğrultusunda; bu çalışmada 1996-2019 yılları arasındaki yıllık veriler kullanılarak Türkiye’nin eğitim, sağlık ve Ar-Ge harcamalarının ekonomik büyümesi üzerine olan etkileri incelenmiştir. Değişkenler arasındaki ilişkilerin belirlenmesinde ARDL sınır testi ve ilişkilerin yönünün belirlenmesinde de Toda-Yamamoto nedensellik testi kullanılmıştır. Analizler, \%5 anlamlılık düzeyinde uzun dönemde eğitim, sağlık ve Ar-Ge harcamaları ile GSYİH arasında anlamlı ve pozitif yönlü bir ilişki olduğunu göstermiştir. Ayrıca, Toda-Yamamoto testi ise her bir değişken ile GSYİH arasındaki nedensellik ilişkinin çift yönlü olduğunu göstermiştir. Sonuç olarak; eğitim, sağlık ve Ar-Ge alanlarında yapılan iyileştirmelerin gelir düzeyini ve dolayısıyla yaşam kalitesini artırdığı söylenebilir. Bu nedenle, Türkiye'de devletin bu alanlara yapacağı yatırımlar önem arz etmekte ve ilgili kurumların bu alanlara yönelik politikalar geliştirilmesi önerilmektedir.

Anabtar Kelimeler: ARDL, AR-GE Harcamaları, Eğitim Harcamaları, Ekonomik Büyüme, Eşbütünleşme, Sağlık

Harcamaları

\section{Determining the Relationship between Education, Health and R\&D Expenditures with} Economic Growth Using ARDL Boundary Test

\begin{abstract}
Mankind is in a constant effort to increase their living standards. However, the way to reach healthier, conscious and quality living standards generally depends on determining the relationships between economic time series in a healthy way and therefore developing a better development strategy. In accordance with this purpose; using annual data for the years between 1996-2019 in this study, its impacts on the economic growth of Turkey's education, health and $\mathrm{R} \& \mathrm{D}$ expenditures were examined. In the study, ARDL boundary test was used to determine the relationships between variables and the Toda-Yamamoto test causality test was used to determine the direction of the relationships. Analysis results showed that there is a significant and positive relationship between education, health and $R \& D$ expenditures and GDP in the long run at the 5\% significance level. In addition, Toda-Yamamoto test results showed that the causality relationship between each variable and GDP is two-way. As a result, arrangements to be made in the education, health and the R\&D area will improve income level and quality of life. Therefore, investment the government of Turkey to these areas is important. In this context, the relevant institutions to develop policies in these areas are recommended.
\end{abstract}

Key Words: ARDL, R\&D Expenditures, Education Expenditures, Economic Growth, Cointegration, Health Expenditures

\section{Atıf İçin / Please Cite As:}

Demir, Y. (2021). Eğitim, Sağlık ve AR-GE Harcamaları ile Ekonomik Büyüme Arasındaki İlişkinin ARDL Sınır Testi ile Belirlenmesi. Manas Sosyal Araştırmalar Dergisi, 10(3), 1758-1770.

Geliş Tarihi / Received Date: 17.04.2021

Kabul Tarihi / Accepted Date: 09.05.2021

\footnotetext{
${ }^{1}$ Dr. Öğr. Üyesi - Van Yüzüncü Yll Üniversitesi İktisadi ve İdari Bilimler Fakültesi, ydemir@yyu.edu.tr 


\section{Giriş}

İnsanoğlu, yaşam standardını artırmak için sürekli bir çaba içerisinde olmuştur. Ancak iyi bir yaşam standardına ulaşabilmek için çoğu kez çabanın tek başına yeterli olmadığı, aynı zamanda bireyin iyi bir eğitim ve bilimsel araştırma gibi birçok farklı imkâna da sahip olması gerekmektedir. Bu nedenle, hem kamu hem de özel sektör tarafından çeşitli alanlarda yatırımların yanı sıra harcamalar da yapılmaktadır. Bu bağlamda yaşam standardı için önemli bir gösterge olan ekonomik büyüme ile bu yatırım veya harcama kalemleri arasındaki ilişkilerin belirlenmesine yönelik araştırmaların kökeni çok geçmişe dayanmaktadır. Günümüzde ise konu hakkında birbirinden farklı birçok bilimsel çalışmaya rastlanılmaktadır. Söz konusu bu harcamalar arasında, ağırlıklı olarak kamu tarafindan finanse edilen eğitim ve sağlık gibi sosyal ihtiyaçların yanı sıra Araştırma ve Geliştirme (Ar-Ge) harcamaları da yer almakta ve Gayri Safi Yurtiçi Hasıla (GSYIH) ile bu üç harcama kalemi arasındaki ilişkinin belirlenmesi ekonomik büyüme hedefler için bir gösterge olmaktadır.

Eğitim, bilim ve kültür alanında toplumun veyahut bireyin gelişimine katkıda bulunan en önemli süreçlerden biridir. Ayrıca, toplumun sosyal gelişmişlik ve ekonomik büyüme süreçlerine de önemli katkısı olduğu bilinmektedir (Kepenek ve Yentürk, 1994, s. 51). Zira iyi eğitim almış işgücünün teknolojik yeniliklere daha açık olması ve yeni teknolojiler ortaya koyabilme yeteneğine sahip olması nedeniyle üretimde bilgiye önem vererek milli hasılanın hızla artmasına katkı sağlamaktadır. Bu bağlamda, eğitim harcamaları kilit bir rol oynamakta ve dolayısıyla eğitim için ayrılan kaynaklar içerisinde kamusal kaynaklar büyük bir pay oluşturmaktadır. Ayrıca eğitimli bir toplum, sağlıklı bir toplumun da temelini oluşturmaktadır. Zira eğitimli bir toplum daha bilinçli bireyler yetiştirmekte ve bu bireyler hem kendi hem de toplum sağlı̆̆ına daha fazla önem vererek kamunun sağlık için ayırdığı kaynaklardaki artışları da minimize etmektelerdir. Böylece, kamu kaynaklarının daha rasyonel bir şekilde kullanılmasını sağlayarak ekonomik büyümeye katkıda bulunulur (Çalcalı, 2019, s. 450-451).

Ekonomik büyümeyi etkileyen önemli faktörlerden birisinin de sağlk olduğu bilinmektedir. Özellikle ekonomik büyüme ve sağlık arasında uzun dönemde pozitif yönlü bir ilişki bulunmaktadır. Ekonomik büyüme oranındaki artış, sadece gelir seviyesini değil aynı zamanda tüketim harcamalarını ve sağlık yatırımlarını da artıracağından, ortalama yaşam süresini uzamaktadır. Böylece sağlık harcamalarının ekonomik büyümeyi ve dolayısıyla yaşam süresini doğrudan etkilediği kabul edilmektedir. Sağllk hizmetlerinin sosyal ve toplumsal faydaları maliyetinden daha yüksek olması nedeniyle gerekli sağlık harcamaları yapılmakta ve bu harcamaların ekonomik büyüme ile ilişkisini önemli kılmaktadır (Erdoğan ve Bozkurt, 2008, s. 25).

Ülkeler, rekabet güçleri ve gelir düzeyleri bakımından karşılaştırıldıklarında yüksek rekabet gücüne sahip olan ülkelerin daha yüksek gelir düzeyine sahip oldukları görülmektedir. Rekabet gücünü etkileyen ana faktörler ise teknolojik ürün üretimi ve patent buluşlarıdır. Böylece, yüksek gelir elde etmenin rekabet gücüne ve rekabet gücünün de katma değeri yüksek teknolojik ürün üretimine bağlı olduğu söylenebilir (Iğgdeli, 2019, s. 2519). Özellikle gelişmekte olan ülkelerde yüksek katma değerli teknolojik ürünler üretilebilmesi Ar-Ge çalışmaları için ayrılan bütçenin artırılmasıyla mümkündür. Ar-Ge harcamalarına paralel olarak teknolojik yenilikler ortaya çıkmakta ve dolayısıyla verimlilik ve ekonomik büyümede de olumlu gelişmeler meydana gelmektedir (Uçak, Kuvat ve Aytekin, 2018, s. 130). Böylece, Ar-Ge için ayrılan harcamalar ile ülkelerin gelişmişlik seviyeleri arasındaki ilişkinin varlığ yadsınamaz bir gerçek olup, bir ülkenin teknoloji yeteneği ve buna bağlı olarak gelişmişlik düzeyi için en önemli göstergelerden birisinin de Ar-Ge olduğu söylenebilir (Tarı ve Alabaş, 2017, s. 2-3). Ar-Ge harcamalarının yenilik üretmede ve dolayısıyla ihracatta rekabetçi olmada önemli bir yerinin olabileceği gözden kaçırılmamalıdır. Bu nedenle Ar-Ge faaliyetlerinin makro etkileri güncel ve önemli bir araştırma alanı olarak öne çıkmaktadır (Coşkun ve Eygü, 2020, s. 234).

Literatür araştırması sonucu, eğitim, sağlık ve Ar-Ge harcamaları için gelişmiş veya gelişmekte olan ülkelerde diğer ülkelere nazaran daha büyük bir bütçe ayrildığı ve bu üç değişkenin ekonomik büyümeyi pozitif yönde etkileyen önemli faktörler olduğu görülmüştür. Bu nedenle bu çalsşmada, Türkiye'de eğitim, sağlık ve Ar-Ge harcamalarının ekonomik büyümeye nasıl bir etki yaptığı ARDL sınır testi kullanılarak, bağımsız değisşkenler ile bağımlı değişken arasındaki nedensellik ilişkisi de Toda-Yamamoto testi kullanılarak belirlenmeye çalışılmışır. 


\section{Literatür Araştırması}

Baldacci, Clements, Gupta ve Cui (2008, s. 1317), 118 gelişmekte olan ülkenin 1971-2000 yllları arasındaki eğitim ve sağlık verilerine panel veri analizi yöntemi uygulayarak eğitim ve sağlık harcamalarının eğitim ve sağlık sermayesi üzerindeki etkisini araştırmışlardır. Araştırma sonuçları, gerek eğitim gerekse sağlık harcamalarının eğitim ve sağlık sermayesini anlamlı ve pozitif yönde etkilediğini göstermişlerdir. Erdoğan ve Bozkurt (2008, s. 25) tarafindan, 1980-2005 yillar1 arasındaki y1llık veriler kullanılarak ekonomik büyüme ve yaşam beklentisi arasındaki ilişki ARDL sınır test yaklaşımıyla belirlenmeye çalışılmıştır. Araştırma sonuçlarına göre, uzun dönemde Türkiye'de ekonomik büyüme ve yaşam beklentisi arasında pozitif bir ilişki olduğunu belirtmişlerdir.

Nasiru ve Usman (2012, s. 95) tarafından, Nijerya'da 1980-2010 y1lları arasında ekonomik büyüme ve sağlık harcamaları arasındaki dinamik ilişki ARDL Sınır ve Granger nedensellik testleriyle incelenmiştir. Sonuçlara göre, uzun dönemde ekonomik büyümeyle sağlık harcamaları arasında bir ilişki saptanmıştır. ARDL yaklaşımıyla ilişkinin yönü belirlenemezken, en az bir yönlü nedensellik ilişkisi olduğu, nedensellik testine göre ise ekonomik büyüme ile sağlık harcamaları arasında çift yönlü güçlü bir ilişki olduğu belirlenmiştir. Ülkeler arasındaki ekonomik büyüme oranlarındaki farklılıkların sağlık farklılıklarıyla önemli ölçüde açıklanması ve sağlığa yapilan yatırımların ekonomik büyümeyi iyileştirmesi nedeniyle Nijerya hükümeti için sağlık yatırımlarının önemi vurgulanmıştır.

Eriçok ve Yılancı (2013, s. 87), kamu harcamaları içindeki eğitim harcamalarının payını inceleyerek eğitim ile ekonomik büyüme etkileşimini ortaya koymaya çalısmışlardır. Bu amaç doğrultusunda eşbütünleşme sınır test yaklaşımı kullanılmış ve ele alınan değişkenler arasında sadece kısa dönemde ve \%10 anlamllık düzeyinde ilişki görülmüştür. Böylece ekonomik büyümenin geçici olarak eğitim harcamalarından etkilendiği ifade edilmiştir. Ayrıca Eygü ve Coşkun (2020, s. 518), beşeri sermaye, inovasyon ve ekonomik büyüme ilişkisini incelemişlerdir. Bu doğrultuda eşbütünleşme testi sonucunda beşeri sermaye, yenilik, işgücü ve sermaye yatırımları ile ekonomik büyüme arasında uzun dönemli ilişki olduğunu belirlemişlerdir.

Pamuk ve Bektas (2014, s. 77-87) tarafindan, 1998-2013 dönemi için Türkiye'de eğitim harcamalarının ekonomik büyümeyi nasıl etkilediği ARDL sınır testi ve Granger nedensellik testi ile araştırlmıştır. ARDL, eğitim harcamaları ile ekonomik büyüme arasında eşbütünleşme ilişkisinin olmadığını gösterirken, nedensellik testi ise değişkenler arasında tek yönlü bir nedensellik ilişkisi olduğunu göstermektedir. Ayrıca, sürdürülebilir bir büyüme ve küresel rekabet gücüne kavuşmak amacıyla eğitime yapılan yatırımların Türkiye ekonomisi için büyük önem arz ettiği vurgulanmıştır. Ancak GSYİH içinden eğitime ayrılan payın yetersiz olduğu, dolayısıyla eğitimin iktisadi büyümeye etkisinin istatistiki olarak anlamsız olduğu ifade edilmiştir.

Başar, Künü ve Bozma (2016, s. 190-200), 1998-2016 dönemleri için Türkiye'de eğitim ve sağllk harcamalarıyla ekonomik büyüme arsındaki ilişkiyi araştırmışlardır. Uzun dönemde eğitim harcamalarının ekonomik büyümeyi anlamlı bir şekilde etkilemediği ve bu durum Türkiye'de işgücüne yeterli düzeyde kalifiyeli ara eleman katılımının eğitim ile karşılanmamasına bağlanmaktadır. Ancak sağlık harcamalarının ekonomik büyümeyi pozitif yönlü ve anlamlı bir şekilde etkilediğini ve sağlık harcamalarındaki 1 birimlik bir artışı ekonomik büyümeyi 1,13 birim artıracağı öngörülmektedir. Ghorbel ve Kalai (2016, s. 36) tarafindan, 1961-2012 dönemleri verileri kullanılarak Tunus'ta yaşam beklentisi ve sağlık harcamalarının ekonomik büyümeye etkisi ARDL sınır test yaklaşımıyla araştırılmıştır. Sonuçlar, özellikle uzun vadede ekonomik büyüme üzerinde beşeri sermaye etkisinin pozitif olduğunu göstermiştir. Ancak uzun vadede ekonomik büyüme ile sağlık harcamaları arasındaki ilişki negatif bulunmuştur. Ayrıca, hem uzun hem de kısa vadede insan sermayesiyle ekonomik büyüme arasında çift yönlü nedenselliğin olmadığı belirlenmiştir.

Akınc1 (2017, s. 387), 2006-2017 ylları arasındaki dönemsel ekonomik büyüme ve eğitim harcamalar1 verilerini ARDL yöntemiyle analiz edilerek eğitim harcamalarının ekonomik büyüme üzerine etkisini araştırmıştır. Analiz sonuçları, uzun dönemde ekonomik büyüme ile eğitim harcamaları arasında istatistiki olarak anlamlı bir ilişki olduğunu göstermektedir. Ayrıca, eğitim harcamalarındaki \%1'lik bir artışa karşıllık ekonomik büyümede kısa dönemde $\% 0,23^{\prime}$ lük bir artış ve uzun dönemde ise $\% 0,86^{\prime}$ 'lk bir artı̧ın meydana gelebileceği belirlenmiştir. Alper (2017, s. 59), 1981-2016 dönemi y1llık verilerini kapsayan bir veri seti kullanarak eğitim, sağlık ve savunma harcamaları ile ekonomik büyüme arasındaki ilişkileri ARDL sınır testi ile araştırmıştır. Eğitim, sağlık ve savunma harcamaları ile ekonomik büyüme arasında pozitif yönlü 
bir ilişki belirlenmiştir. Eğitim harcamalarında oluşabilecek \%1'lik bir artışın ekonomik büyümeyi \%1,33 ve sağlık harcamalarında oluşabilecek \%1'lik bir artışı ise ekonomik büyümeyi \%0,17 artırabileceği öngörülmüştür. Köprücü ve Sarıtaş (2017, s. 77), Türkiye'ye ait 1980-2013 dönemlerini kapsayan bir veri seti ile ekonomik büyüme ve eğitim arasındaki uzun dönemli ilişkiyi Johansen test istatistiği ve ARDL sınır test yaklaşımlarıyla araştırmışlardır. Sonuçlara göre, eğitim düzeyinin ekonomik büyümeye neden olduğu, ancak gelirin eğitim düzeyine neden olmadığ1 vurgulanmıştır. Sunde (2017, s. 70), Mauritius'taki eğitim harcamaları ve ekonomik büyüme arasındaki ilişki, 1976-2016 dönem verileri kullanılarak ARDL sınır testi yaklaşımıla incelemektedir. Granger testi, Mauritius'ta eğitim harcamalarının ekonomik büyümeye kısa dönemde neden olduğunu ve bu nedenselliğin tek yönlü olduğunu ortaya koymuştur. Ayrıca eğitim harcamaları ile ekonomik büyüme arasındaki ilişkinin uzun dönemli ve pozitif yönlü olduğu belirlenmiş, eğitime yatırımların ekonomik büyümeyi artırdığı ortaya konulmuştur. Tarı ve Alabaş (2017, s. 2), Türkiye'nin 1990-2014 yılları arasındaki ekonomik büyüme ve Ar-Ge harcamaları verilerine ARDL modeli uygulamış, Ar-Ge harcamalarının ekonomik büyümeye olan etkisini incelemişlerdir. Gerek kısa gerekse uzun dönemde Ar-Ge harcamalarının ekonomik büyümeyi pozitif yönde etkilediği ortaya konulmuştur. Türkiye için sürdürülebilir bir ekonomik büyümede uzun dönemli Ar-Ge harcamalarının planlı bir şekilde arttırllmasının önem arz ettiği vurgulanmıştır.

Ifa ve Guetat (2018, s. 234), 1980-2015 döneminde Tunus ve Fas'ta kamu eğitim harcamalarının kişi başına GSYİH üzerindeki etkisini ARDL yaklaşımı ile araştırmışlardır. Ampirik sonuçlara göre, kısa vadede, Fas'ta eğitime yapılan kamu harcamaları ile kişi başı GSYİH arasındaki ilişki pozitif olarak, Tunus'ta ise negatif olarak bulunmuştur. Uzun vadede ise iki ülkede de eğitime yapılan kamu harcamalarının kişi başına düşen GSYİH'yi artırdığı, ancak Fas'ta bu etkini daha yüksek olduğu belirlenmiştir. Kızıl ve Ceylan (2018, s. 206-207) tarafından, Türkiye'deki sağlık harcamalarının ekonomik büyümeye olan etkisi incelenmişlerdir. 65 yaş üstü nüfusun ve sağlık harcamalarının ekonomik büyüme üzerine olan etkisini incelemek amaciyla bu değişkenlere ait 1979-2015 yılları arasındaki veriler; ARDL yaklaşımı, CCR, DOLS ve FMOLS tahmin yöntemleri ile analiz edilmiştir. Analiz sonuçları, kişi başına düşen sağlık harcamaları ile ekonomik büyüme arasında istatistiki olarak anlamlı ve pozitif bir ilişki olduğunu göstermektedir. Uzun dönemde kişi başı sağlık harcamalarında meydana gelecek \%1'lik artışın, kişi başı GSYİH'yi \%0,412 oranında artıracağı, ancak 65 yaş üzeri nüfustaki değişimin kişi başı GSYİH'yi etkilemeyeceği gözlenmiştir. Kouton (2018, s. 22), 1970-2015 arasındaki verilere Toda-Yamamoto nedensellik ve ARDL sınır testlerini uygulayarak Fildişi Sahili için ekonomik büyüme ile eğitim harcamaları arasındaki ilişkiyi incelemiştir. Kamu eğitim harcamalarının ekonomik büyüme üzerine uzun vadede negatif ve anlamlı olan, kısa vadede ise pozitif ve anlamlı olmayan bir etki oluşturduğunu ifade etmiştir. Ayrıca, eğitim harcamalarından ekonomik büyümeye doğru tek yönlü bir nedensellik ilişkisinin olduğunu göstermiştir. Fildişi Sahili'nde kamu eğitim harcamalarının ekonomik büyümeyi teşvik etmediğini ve bu durum düşük kamu eğitim harcamalarına, dolayısıyla ekonomik büyümeye dönüştürülmesindeki verimsizliğe bağlanmıştır. Uçak vd. (2018, s. 129) tarafından, 1990-2016 döneminde Türkiye'de reel GSYH ve toplam Ar-Ge harcamaları arasındaki ilişki ARDL sınır testi ile analiz edilmiştir. ARDL modeliyle, uzun dönemde Ar-Ge'nin GSYH üzerinde anlamlı ve pozitif etkisinin olduğu, Ar-Ge'deki \%1'lik bir değişimin GSYH'de \%5,92'lik değişime neden olduğu belirlenmiştir. Ayrıca hata düzeltme model katsayısını istatistiki olarak anlamlı, negatif ve mutlak değerini 1'den büyük bulmuşlardır. Böylece, kısa dönemde oluşan dalgalanmaların uzun dönemde dengeye geleceği ve Türkiye'de Ar-Ge harcamalarındaki artışın uzun dönemde ileri teknolojili ürün ihracatını sağlayarak büyüme ve cari denge üzerinde pozitif etkiye sahip olabileceği ifade edilmiştir.

İğdeli (2019, s. 2517), 1990-2016 dönem verilerini kullanarak Türkiye'de eğitim ve Ar-Ge harcamalarıla ekonomik büyüme arasındaki ilişki varlığını ARDL sınır testi ile incelemiştir. Uzun dönemde, Ar-Ge ve eğitim harcamalarının ekonomik büyümeyi pozitif yönde etkilediği, ele alınan üç değişken arasında anlamlı bir ilişki olduğu saptanmıştır. Ayııca, Ar-Ge harcamalarından eğitim harcamalarına ve ekonomik büyümeye, ekonomik büyümeden ise eğitim harcamalarına doğru \%5 anlamlılık düzeyinde tek yönlü bir nedensellik olduğunu göstermiştir.

\section{Materyal ve Yöntem}

Çalışmada, Türkiye'nin eğitim harcamaları $(\mathrm{EH})$, sağllk harcamaları $(\mathrm{SH})$ ve AR-GE harcamaları (AGH) ile GSYIH verilerinden oluşan bir veri seti materyal olarak kullanılmıştır. Dünya Bankasına ait "https://databank.worldbank.org/source/world-development-indicators" internet adresinden elde edilen 
bu veri seti 1996-2019 yılları arasındaki 24 yıllık zamanı kapsamaktadır. Yöntem olarak ARDL sınır testi kullanılmış ve gerekli analizler Eviews 9 paket programı ile yapılmıştır.

\section{Zaman Serilerinde Durağanlık Testleri}

Zaman serilerinde durağanlık tahminlemenin ön şartlarından birisidir. Durağanlık, bir serisinde ortalama ve varyansın zamanla değişmemesi olayı olarak ifade edilmekte ve durağan olan bir serinin birim kök içermediği kabul edilmektedir. Zaman serilerinde durağanlık şartı sağlandığında, uzun dönemde bu zaman serilerinin kendi ortalamaları etrafinda dalgalanarak ortalamaya dönme eğiliminde oldukları ve iki zaman periyodu arasındaki kovaryansın değeri, sadece iki zaman periyodu arasındaki farka veya mesafeye bağlı olduğu söylenebilir. Böylece, serilere uygulanan bir birimlik şokun etkisinin geçici olduğu durumlarda, durağan olan seriler ortalamaya dönme eğilimi göstermektedir (Gujarati ve Porter, 2009, s. 740). Değişkenlerin birim kök içermesi serilerin durağan olmadığını göstermekte ve durağan olmayan serilerle yapılan analizlerin ise güvenilir sonuçlar vermediği belirlenmiştir. Zira değişkenler arasında, sahte regresyon olarak tanımlanan bir ilişki meydana gelebilmektedir (Altun, İşleyen ve Görür, 2018, s. 231). Bu çalışsmada, serilerin durağanlığ1 Genişletilmiş Dickey-Fuller (Augmented Dickey-Fuller, ADF) ve Phillips-Perron (PP) birim kök testleriyle belirlenmeye çalışılmıştır.

Genişletilmis Dickey-Fuller Birim Kök Testi. ADF birim kök testi, Dickey ve Fuller (1979) (DF) birim kök testinde otokorelasyon probleminin göz ardı edilmesi üzerine önerilmiştir (Dickey ve Fuller, 1981). Bu testte, modelde bulunan hata terimlerinin otokorelasyonlu olduğu kabul edilmiş ve otokorelasyon problemini gidermek amacıyla bağımlı değişkenin gecikmeli terimleri modele dâhil edilmiştir. ADF'de uygun gecikmeli terim sayısina karar vermede genellikle Schwarz bilgi kriteri (SIC) veya Akaike bilgi kriteri (AIC) kullanılmaktadır. SIC büyük örneklemlerde daha güvenilir ve AIC ise sonlu örneklemlerde daha güçlü sonuçlar vermektedir. Bu testte otokorelasyon problemini aşmak için $\mathrm{AR}(\mathrm{p})$ süreçli denklemler geliştirilmiştir.

$$
\begin{aligned}
& \Delta Y_{t}=\beta_{0}+\theta Y_{t-1}+\sum_{i=1}^{p} \alpha_{i} \Delta Y_{t-i}+\varepsilon_{t} \\
& \Delta Y_{t}=\beta_{0}+\beta_{1} t+\theta Y_{t-1}+\sum_{i=1}^{p} \alpha_{i} \Delta Y_{t-i}+\varepsilon_{t}
\end{aligned}
$$

Bu eşitliklerde, $\Delta Y_{t}$; değişkenlerin birinci farkını, $Y_{t-1}$; gecikmeli fark trendini, t; trendi, p; uygun gecikme uzunluğunu; $\varepsilon_{t}$; hata terimini, $\beta_{0}$; sabit terimi, $\beta_{1}, \theta$ ve $\alpha$ ise ilişki katsayllarını göstermektedir (Pata, Yurtkuran ve Kalça, 2016, s. 264). Eşitlik (1) sabit model için ve eşitlik (2) ise sabit+trendli model için verilmiştir.

Pbillips Perron Birim Kök Testi. Phillips ve Perron (1988) tarafindan, hata terimleri arasındaki otokorelasyonu düzelten non-parametrik bir test ortaya konulmuştur. Otoregresif-hareketli ortalama süreci (ARMA) kullanılarak bu non-parametrik testte modeller oluşturulmuştur. Bu test, zaman serilerinin durağanlık analizinde DF ve ADF testlerinin zayıflığına karşı geliştirilmiş ve trend içeren zaman serilerinde bu testlerden daha güçlü sonuçlar vermektedir. Phillips Perron testi eşitlik (3) veya (4) ile gösterilmektedir.

$$
\begin{aligned}
y_{t} & =\hat{\mu}+\hat{\alpha} y_{t-1}+\hat{\varepsilon}_{t} \\
y_{t} & =\tilde{\mu}+\tilde{\beta}\left(t-\frac{1}{2} T\right)+\tilde{\alpha} y_{t-1}+\tilde{\varepsilon}_{t}
\end{aligned}
$$

Burada, T gözlem sayısını, $\varepsilon$ hata terimini, $\mu, \alpha$ ve $\beta$ ise en küçük kareler (EKK) regresyonu katsayılarını göstermektedir.

Eşitlik (3) ve (4)'de verilen modellere sıfır olmayan sabit bir terim eklendiğinde veri oluşturma süreci, t-istatistikleri ve katsayılar aynı kalacağından bu eşitlikler yerine eşitlik (5) kullanılabilir.

$$
y_{t}=\mu+\alpha y_{t-1}+\varepsilon_{t} \quad t=1,2, \ldots n
$$

ADF, DF ile ayn kritik tablo değerlerini ve Phillips ve Perron (1988, s. 338) testide DF ile aynı limit dağılımına sahip olduğundan $Z$ istatistikleri de, DF kritik tablo değerlerini kullanmaktadır. Ayrıca bu birim kök testleri için hipotezler aşağıdaki gibi kurulmaktadır.

$\mathrm{H}_{0}: \rho=1$ veya $\delta=0$ (Seri durağan değildir veya seri birim kök içermektedir) 
$\mathrm{H}_{1}: \rho<1$ veya $\delta<0$ (seri durağandır veya seri birim kök içermemektedir).

\section{Eşbütünleşme Testi}

Ekonometride yaygın bir şekilde kullanılan ve zaman serileri analizinin temelini oluşturan eşbütünleşem testleri, zaman serileri arasındaki olası ilişkileri ortaya koymak amacıyla gerçekleştirilmektedir. Eşbütünleşme analiz yöntemi, Granger (1981) ve Engle ve Granger (1987) tarafindan geliştirilmiş ve günümüzde de güncelliğini yitirmeyerek ekonometrik modeller arasında önemli bir ağırlığa sahiptir. Zaman serilerinin büyük bir kısmının durağan olmadığı bilinmektedir. Durağan olmayan zaman serileri ile yapılan analizler çoğunlukla gerçek ilişkiyi yansıtmamakta ve sahte ilişkinin ortaya konulmasına yol açmaktadır (Engle ve Granger, 1987, s. 275). Sahte regresyonun önüne geçmek amacıyla durağan olmayan bu seriler değil, bunların birinci farkları alınarak modelleme gerçekleştirilmektedir. Ancak, bu durum uzun dönem denge için önemli olan bazı bilgilerin kaybedilmesine neden olmaktadır. Böylece seriler arasında var olan uzun dönemli ilişki, fark alınma yöntemi ile ortadan kaldırilabilir. Bu sorunu aşarak değişkenler arasındaki ilişkileri belirlemek için eşbütünleşme analizi önerilmektedir (Demir ve Görür, 2020, s. 24).

Gecikmesi Dağttılmış Otoregresif Sınır Testi. En Küçük Kareler (EKK) yöntemine dayanan Gecikmesi Dağıtılmış Otoregresif Sınır Test (ARDL, Autoregressive Distributed Lag Bound Test) yaklaşımı, değişkenler arasındaki dinamik (otoregresif) ilişki yapısının açıklanmasında kullanılmaktadır (Pesaran ve Shin, 1999, s. 371). Zaman serisi kullanılan regresyon analizinde, model bağımsız değişkenlerin sadece şimdiki değerlerini değil aynı zamanda gecikmeli değerlerini de içeriyorsa bu modele gecikmesi dağıtılmış model (distributed lag model) denilmektedir. Model, bağımsız değişkenleri arasında bağımlı değişkenin bir ya da birden fazla gecikmeli değerlerini içeriyorsa bu modele de ardışı bağlanımlı model denilmektedir. Bu iki model sırasıyla eşitlik (6) ve (7) ile gösterilmiştir.

$$
\begin{aligned}
& Y_{t}=\alpha+\beta_{0} X_{t}+\beta_{1} X_{t-1}+\beta_{2} X_{t-2}+\cdots+\varepsilon_{t}=\sum_{i=0}^{k} \beta_{i} X_{t-i}+\varepsilon_{t} \\
& Y_{t}=\alpha+\sum_{j=0}^{q} \beta_{j} X_{t-j}+\sum_{i=1}^{p} \varphi_{i} X_{t-i}+\varepsilon_{t}
\end{aligned}
$$

Burada; $q$ 'lar $x_{t}$ üzerindeki, $p^{\prime}$ ler ise $y_{t}$ üzerindeki gecikmeleri göstermektedir. Engle-Granger (1981) yönteminde, değişkenler arasında eşbütünleşme ilişkisi olup olmadığına karar verilirken, tahmin edilen uzun dönem denge sapmasından yararlanılır. Değişkenlerin gecikmeli değerlerinin dikkate alınmaması bir spesifikasyon hatasına yol açmaktadır. Bu nedenle Phillips ve Loretan (1991) tarafindan, eşbütünleşme ilişkisinin belirlenmesinde ARDL modeli önerilmiştir (Akdağ, 2019, s. 231). ARDL sınır testi yaklaşımı üç aşamadan oluşmaktadır. Bunlar, modelde yer alan değişkenler arasındaki eşbütünleşme ilişsisinin kısıtsız hata düzeltme modeli (UECM) ile incelenmesi, bilgi kriterlerine göre uygun gecikme uzunluğunun belirlenmesi ve değişkenler arasında uzun dönemde eşbütünleşme ilişkisi olup olmadığının tespit edilmesi, şayet ilişki varsa, uzun ve kısa dönem katsayılarının belirlenmesi şeklinde sıralanabilir (Narayan ve Smyth, 2006, s. 337; Özcan, 2017, s. iii). ARDL sınır testi yaklaşımında eşbütünleşme ilişkisinin belirlenmesi için hipotezler;

$$
\begin{aligned}
& H_{0}: y_{1}=y_{2}=\ldots=0, \text { Eşbütünleşme ilişkisi yoktur, } \\
& H_{1}: y_{1} \neq y_{2} \neq \ldots \neq 0, \text { Eşbütünleşme ilişkisi vardır, şeklinde kurulmaktadır. }
\end{aligned}
$$

F istatistiğinin hesaplanan değeri, üst sınır değerinden büyük olduğu durumda $H_{0}$ hipotezi reddedilerek değişkenler arasında eşbütünleşmenin olduğu ifade edilirken, alt sınır değerinden küçük olduğu durumda ise $H_{0}$ hipotezi kabul edilerek değişkenler arasında eşbütünleşmenin olmadığı ifade edilmektedir. F istatistik değeri, alt ve üst sınır değerleri arasında ise eşbütünleşme hakkında karar alınamamaktadır.

ARDL yaklaşımının diğer eşbütünleşme yöntemlerine göre en büyük avantajı, değişkenlerin hangi derecelerde durağan hale getirildiğine bakılmaksızın bunları eş zamanlı olarak analize alabilmesidir. Böylece, bazı değişkenler düzeyde $\mathrm{I}(0)$ durağanken, geriye kalanlar ise farkları alınarak I(1 gibi) durağanlaştırıldıktan sonra bunlar arasında uzun dönemde eşbütünleşme olup olmadığı sınanabilir. Ayrıca, 
küçük örneklem boyutlarında kısıtsız hata düzeltme modeliyle daha iyi sonuçlar vermesi, seri korelasyon ve içsellik sorunlarını önlemesi ARDL yaklaşımının diğer önemli avantajlarıdır (Mah, 2000, s. 240; Narayan, 2004, s. 204).

\section{Toda-Yamamoto Nedensellik Testi}

Literatürde daha yaygın olarak Granger nedensellik testi kullanılmaktadır. Bu testin kullanılabilmesi için serilerin durağan veya aynı dereceden bütünleşik olması gerekmektedir. Seriler aynı dereceden durağan değilse bu testin uygulanması hatalı sonuçlar verebilmektedir. Ayrıca, serilerin farkları alınarak seriler durağanlaştırıldığında, belli bir oranda veri kaybı meydana gelmektedir. Bu nedenle, bu tür serilerin analizinde Granger nedensellik testi yerine Toda-Yamamoto nedensellik testi tercih edilmektedir. Zira vektör otoregresif (VAR) modele dayanan Toda-Yamamoto (1995) testi, modeldeki değişkenlerin ayn1 dereceden durağan olup olmadığına bakmaksızın düzeyde model tahmini yapabilmektedir (Meçik ve Koyuncu, 2020, s. 2625-2626).

Toda-Yamamoto testinin uygulanabilmesi için gecikme uzunluğunun $(p)$ ve maksimum bütünleşme derecesinin $\left(d_{\max }\right)$ belirlenmesi gerekmektedir. Modelin doğru belirlenmesi ve seviyede daha başarılı sonuçların elde edilmesi bu iki parametrenin belirlenmesine bağlıdır. Bu iki parametre belirlendikten sonra, $p+d_{\text {max }}$ boyutunda $\operatorname{VAR}\left(\operatorname{VAR}_{\left(p+d_{\max }\right)}\right)$ modeli oluşturularak Toda-Yamamoto testi uygulanmaktadir. Bu durumda ilgili VAR modeli,

$$
\begin{aligned}
& Y_{t}=\alpha_{0}+\sum_{i=1}^{p+d_{\max }} \alpha_{1 i} Y_{t-1}+\sum_{i=1}^{p+d_{\max }} \alpha_{2 i} X_{t-1}+\mu_{y t} \\
& X_{t}=\beta_{0}+\sum_{i=1}^{p+d_{\max }} \beta_{1 i} X_{t-1}+\sum_{i=1}^{p+d_{\max }} \beta_{2 i} Y_{t-1}+\mu_{x t}
\end{aligned}
$$

eşitlikleri ile gösterilmektedir. Ancak Toda-Yamamoto nedensellik işleminin uygulanabilmesi için $d_{\max }$ değerinin, $p$ değerini aşmaması gerekmektedir (Meçik ve Koyuncu, 2020, s. 2626; Riyath, 2018, s. 7).

\section{Bulgular}

Değişkenlerin durağanlık durumlarını analiz etmek amacıyla ADF ve PP birim kök testleri kullanılmış ve bu testlere ait sonuçlar Tablo 1'de verilmiştir.

\begin{tabular}{|c|c|c|c|c|c|c|c|c|c|}
\hline \multirow[b]{3}{*}{ Test } & \multirow[b]{3}{*}{ Değişken } & \multicolumn{4}{|c|}{$I(0)$} & \multicolumn{4}{|c|}{$I(1)$} \\
\hline & & \multicolumn{2}{|c|}{ Sabit } & \multicolumn{2}{|c|}{ Sabit+Trendli } & \multicolumn{2}{|c|}{ Sabit } & \multicolumn{2}{|c|}{ Sabit+Trendli } \\
\hline & & $t$-bar & $p$ & $t$-bar & $p$ & $t$-bar & $p$ & $t$-bar & $p$ \\
\hline \multirow{4}{*}{$\frac{1}{8}$} & GSYIH & $-2,087$ & 0,002 & $-3,140$ & 0,003 & & & & \\
\hline & $\mathrm{EH}$ & $-2,119$ & 0,197 & $-3,318$ & 0,293 & $-2,251$ & 0,001 & $-3,203$ & 0,001 \\
\hline & $\mathrm{SH}$ & $-2,381$ & 0,371 & $-3,294$ & 0,411 & $-2,301$ & 0,001 & $-3,004$ & 0,020 \\
\hline & $\mathrm{AGH}$ & $-2,162$ & 0,276 & $-3,217$ & 0,420 & $-2,347$ & 0,001 & $-3,149$ & 0,001 \\
\hline \multirow{4}{*}{$\S$} & GSYİH & $-2,310$ & 0,001 & $-3,069$ & 0,002 & & & & \\
\hline & $\mathrm{EH}$ & $-2,437$ & 0,410 & $-3,501$ & 0,381 & $-2,617$ & 0,001 & $-3,314$ & 0,001 \\
\hline & $\mathrm{SH}$ & $-2,379$ & 0,398 & $-3,621$ & 0,390 & $-2,304$ & 0,001 & $-3,291$ & 0,002 \\
\hline & $\mathrm{AGH}$ & $-2,416$ & 0,278 & $-3,489$ & 0,461 & $-2,450$ & 0,001 & $-3,481$ & 0,001 \\
\hline
\end{tabular}

Tablo 1. Birim Kök Test Sonuclar

Tablo 1 incelendiğinde her iki test için de, düzeyde hem sabit hem de sabit +trendli modelde, GSYIH için $H_{0}$ hipotezinin ret edildiği ( $\left.\mathrm{p}<.05\right)$, böylece GSYIH serisinin düzeyde durağan olduğu kabul edilir. Ancak iki testte de düzeyde hem sabit hem de sabit+trendli modelde, eğitim harcamaları (EH), sağlık harcamaları $(\mathrm{SH})$ ve ARGE harcamaları $(\mathrm{AGH})$ serileri için $H_{0}$ hipotezinin kabul edildiği (p>.05) ve böylece bu değişkenlerin \%5 anlamlılık düzeyinde durağan olmadığı yani birim kök içerdikleri belirlenmiştir. Durağan olmayan serilerin durağan hale getirilmesi için bunların birinci dereceden farkları alınmış ve daha sonra bu değişkenlerin durağanlığ yeniden sınanmıştır. Fark alma işleminden sonra birim kök sınaması için kullanılan iki test ve iki modele ile yapılan analizlerde, EH, SH ve AGH değişkenleri için 
$H_{0}$ hipotezi reddedilmiştir $(\mathrm{p}<.05)$. Böylece bu değisskenlerin birinci dereceden farkları alındıktan sonra bunların \%5 anlamlılık düzeyinde durağan hale getirildikleri yani birim kök içermedikleri söylenebilir.

Değişkenlerin farklı seviyelerde durağanlık göstermesi durumunda eşbütünleşme analizi için ARDL yaklaşımının kullanılması daha uygundur. $\% 1, \% 5$ ve $\% 10$ anlamllık düzeyinde değişkenler arasında ARDL sınır testine göre eşbütünleşmenin olup olmadığı Tablo 2'de gösterilmiştir.

Tablo 2. ARDL Eşbütünleşme Sinır Testi

\begin{tabular}{|c|c|c|c|c|}
\hline \multirow{2}{*}{ Bağımsız Değişken sayısı (k) } & \multirow{2}{*}{$F$ istatistiği } & \multirow{2}{*}{ Anlamlılık Düzeyi } & \multicolumn{2}{|c|}{ Kritik Değerler } \\
\hline & & & Alt Sinir & $\ddot{U}$ st Sinir \\
\hline \multirow[t]{3}{*}{3} & & $\% 1$ & 1,73 & 2,87 \\
\hline & 17,3559 & $\% 5$ & 2,27 & 3,77 \\
\hline & & $\% 10$ & 2,45 & 3,69 \\
\hline
\end{tabular}

Tablo 2 incelendiğinde, $\mathrm{F}$ istatistik değerinin, $\% 5$ anlamlllık düzeyinde üst sınır değerinden büyük olduğu görülmektedir. Dolayısıyla $H_{1}$ hipotezi kabul edilerek değişkenler arasında eşbütünleşmenin olduğu belirlenmektedir. Değişkenler arasında uzun dönemli bir ilişki olduğu belirlendikten sonra bu ilişkiye ait parametreler EKK yöntemine dayanan ARDL modeli ile tahmin edilmiş ve tahmin sonuçları Tablo 3'te verilmiştir.

Tablo 3. $A R D L(1,2,2,2)$ Model Tahminleri

\begin{tabular}{lcccc}
\hline Değişken & Katsayılar & Standart Hata & $\boldsymbol{t}$ - istatistik & $\boldsymbol{p}$ \\
\hline Sabit (c) & 0,017893 & 0,001478 & 6,571362 & 0,031 \\
GSYİH(-1) & 0,103647 & 0,078312 & $-2,741693$ & 0,013 \\
EH (-1) & 0,136402 & 0,032147 & $-2,317895$ & 0,025 \\
EH (-2) & 0,112365 & 0,036415 & $-2,017852$ & 0,031 \\
SH (-1) & 0,127853 & 0,063219 & $-2,378901$ & 0,019 \\
SH (-2) & 0,107524 & 0,001436 & $-2,368710$ & 0,021 \\
AGH (-1) & 0,084178 & 0,002143 & $-2,531472$ & 0,001 \\
AGH (-2) & 0,074123 & 0,002014 & $-2,389014$ & 0,003 \\
\hline P< 05
\end{tabular}

Tablo 3 incelendiğinde, ARDL (1, 2, 2, 2) modelinde yer alan değişkenlere ait değerler görülmektedir. Tablo 3'e göre, tüm değişkenin anlamlı $(\mathrm{p}<.05)$ ve katsayılarının da pozitif olduğu belirlenmiştir. $\mathrm{Bu}$ sonuçlar model tahmininin başarılı olduğunu göstermektedir.

ARDL modeli ile yapılan analizlerde göz ardı edilmemesi gereken önemli unsurlardan birisi de EKK'nın temel varsayımlarıdır. EKK temel varsayımlarına ait sonuçlar tablo 4'te verilmiştir.

Tablo 4. ARDL Tanisal Testleri

\begin{tabular}{lcc}
\hline \multicolumn{1}{c}{ Tanisal Testler } & Test İstatistikleri & $\boldsymbol{p}$ \\
\hline$R^{2}$ & 0,740136 & \\
Adjusted $R^{2}$ & 0,726520 & 0,002 \\
F- İstatistik & 11,143026 & 0,371 \\
Breush-Godfrey LM Test & 0,610363 & 0,341 \\
ARCH Test & 2,490170 & 0,530 \\
Jarque-Bera Normality Test & 0,593076 & 0,501 \\
Ramsey-Reset Test & 1,701633 & \\
\hline
\end{tabular}

Yüzde olarak ifade edilen $\left(R^{2}\right)$ belirleme katsayısı, 0 ile 1 arasında değişmekte ve bağımsız değişkenlerin bağımlı değişkendeki varyansı hangi oranda açlkladığını göstermektedir. Tablo 4'te, GSYİH'nin yaklaşık \%74'nün EH, SH ve AGH tarafindan açıklandığ1 görülmektedir. Adjusted (Düzeltilmiş) $R^{2}$ ile model genelleştirilmiş ve eğer model popülasyondan genelenmiş olsaydı GSYİH'daki varyasyonun yaklaşık \%73'ü EH, SH ve AGH tarafindan açılanmış olacaktı. Tahmin edilen modelde otokorelasyonun olup olmadığ 1 Breush-Godfrey LM testiyle, değişen varyans sorunu ARCH testiyle, hataların normal dağılıma sahip olup olmadığı Jarque-Bera normallik testiyle ve model kurma hatası olup 
olmadığ1 ise Ramsey-Reset testiyle sınanmaktadır. Bu testlerin her biri için ayrı ayrı hesaplanan $\mathrm{p}$ değerlerinin verilen önem seviyesiyle karşılaştırılarak sonuçların anlamlılığı hakkında yorumlar yapılmaktadır. Hesaplana p değeri kritik değerden büyükse; Breush-Godfrey LM testine göre otokorelasyonun, ARCH testine göre değişen varyans sorununun ve Ramsey-Reset testine göre ise model kurma hatasının olmadığı ve Jarque-Bera normallik testine göre hataların normal dağıldığı kabul edilmektedir. Tablo 4 incelendiğinde, bu dört test için de hesaplanan p değerlerinin 0,05 'ten büyük olduğu görülmektedir. Bu p değerlerine göre; Breush-Godfrey LM testi ile otokorelasyonun olmadığ1, ARCH testi ile değişen varyans sorununun olmadığ1, Jarque-Bera normallik testi ile hataların normal dağıldığı ve Ramsey-Reset testi ile de model kurma hatasının olmadığı belirlenmiştir. Tablo 5'de, uzun dönem ARDL modeli ile hesaplanan parametrelere ait katsayılar ve olasılık değerleri verilmiştir. Bu tablodaki bilgilerden yararlanılarak değişkenler arasındaki uzun dönemli ilişkinin durumu belirlenebilir.

Tablo 5. Užn Dönem ARDL Eşbütünleşme Sonuslarn

\begin{tabular}{lcccc}
\hline Değişken & Katsayılar & Standart Hata & $\boldsymbol{t}$ & $\boldsymbol{p}$ \\
\hline Sabit & 0,107241 & 0,003370 & 3,104562 & 0,023 \\
EH & 0,078132 & 0,024813 & $-2,214690$ & 0,001 \\
SH & 0,089701 & 0,015607 & $-2,163147$ & 0,001 \\
AGH & 0,013762 & 0,023478 & $-2,413501$ & 0,002 \\
\hline
\end{tabular}

Çalısmada, GSYIH bağımlı değişkeni, EH, SH ve AGH ise bağımsız değişkenleri göstermektedir. Tablo 5'e göre, EH, SH ve AGH değişkenleri ile GSYIH değişkeni arasında anlamlı ( $<<.05)$ ve pozitif yönlü bir ilişki olduğu söylenebilir. Ayrıca, EH'de meydana gelecek 1 birimlik artış, GSYIH'da 0,078 birimlik bir artışa, SH'de meydana gelecek 1 birimlik artış, GSYIH'da 0,089 birimlik bir artı̧a ve AGH'de meydana gelecek 1 birimlik artış ise GSYİH'da 0,013 birimlik bir artışa yol açmaktadır. Böylece Türkiye'de EH, SH ve AGH'nın GSYİH üzerindeki etkileri karşılaştırıldığında, en büyük etkinin SH ait olduğu söylenebilir. Sonuç olarak GDP ile verilen değişkenler arasında, $\mathrm{GDP}=0,107+0,078 * \mathrm{EH}+0,089 * \mathrm{SH}+0,013 * \mathrm{AGH}$ şekilde bir model kurulmaktadır.

Değişkenlerde herhangi bir yapısal kırılmanın olup olmadığı belirlenerek, ARDL modelinin kararlılığı araştırllmış ve bunun için geri dönüşlü hata terimleri karelerinden yararlanan CUSUM ve CUSUMQ grafikleri kullanılmıştır. Bu grafiklerde, değişkenler kritik sınırlar arasında kalıyorsa ARDL modelinin kararlı olduğu ve böylece model katsayılarının istikrarlı olduğu belirlenir.

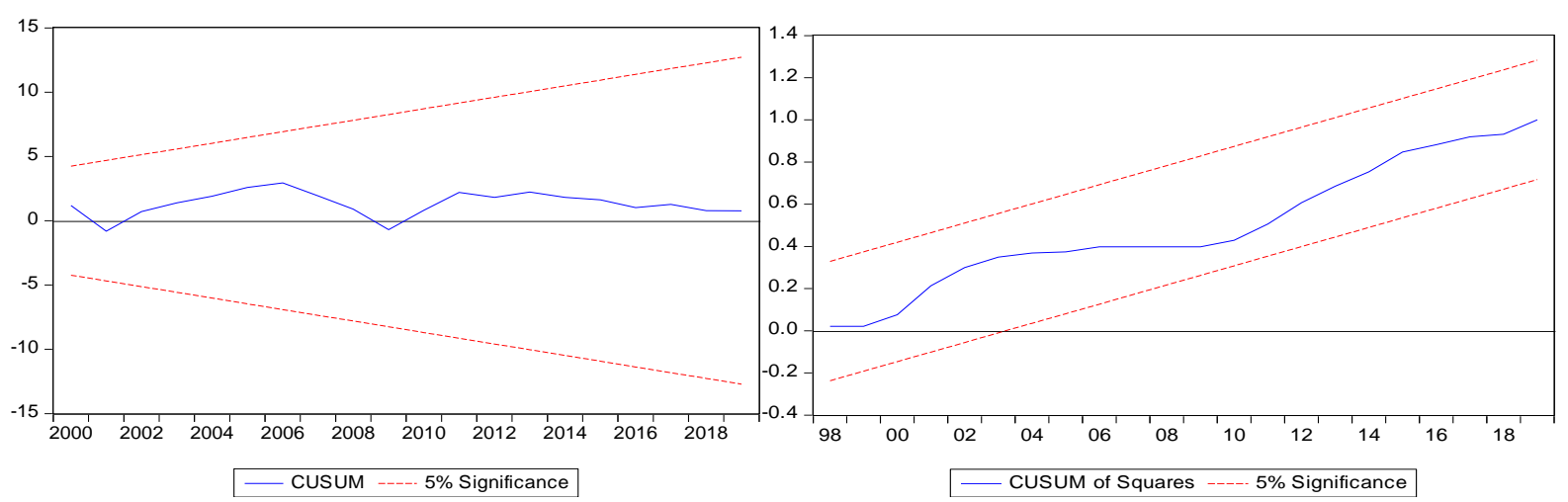

Şekil 1. Ekonomik Büyüme Modeli için CUSUM ve CUSUMQ Grafikleri

Grafik 1'de, tahmin edilen ARDL modelinin kararlllı̆̆1 gösterilmektedir. CUSUM ve CUSUMSQ grafikleri incelendiğinde, $\% 5$ anlamlılık düzeyinde değişkenlerin kritik sınırlar arasında kaldığ1 belirlenmiştir. Böylece, değişkenlerde herhangi bir yapısal kırılmanın olmadı̆̆ı ve ARDL sınır testi ile hesaplanan uzun dönem katsayılarının istikrarlı olduğu gözlenmiştir.

Değişkenler arasındaki nedensellik yönü için VAR modeli ile uygun gecikme uzunluğu belirlenmiş ve daha sonra Toda-Yamamoto testi ile nedensellik analizi yapılmıştır.

Tablo 6. ARDL Modeli için Gecikme Uzunluklar

\begin{tabular}{cccccc}
\hline Gecikme & $\boldsymbol{L} \boldsymbol{R}$ & $\boldsymbol{F P E}$ & $\boldsymbol{A I C}$ & $\boldsymbol{S I C}$ & $\boldsymbol{H Q}$ \\
\hline 1 & 49,34782 & 3415,2713 & 22,06270 & 28,28041 & 26,03715 \\
2 & $49,01547^{*}$ & $3124,016^{*}$ & $21,10419^{*}$ & $27,07614^{*}$ & $25,00143^{*}$
\end{tabular}




\begin{tabular}{llllll}
\hline 3 & 51,04861 & 3361,179 & 21,50793 & 29,10083 & 25,70391 \\
4 & 53,07126 & 3641,061 & 22,16820 & 30,00731 & 26,00617 \\
\hline
\end{tabular}

Tablo 6'da, Ardışı modifiye edilmiş (LR) test istatistiği, Son kestirim hatası (FPE), Akaike bilgi kriteri (AIC), Schwarz bilgi kriteri (SIC) ve Hannan-Quinn bilgi kriteri (HQ) dikkate alınarak gecikme uzunluğuna karar verilmiştir. Her ne kadar materyal ve yöntem bölümünde uygun gecikme uzunluğunun belirlenmesinde AIC ve SIC yöntemlerinden yararlanılacağı ifade edilmiş olsa da bu iki yöntemin güvenirliliği için Tablo 6'da altı farklı yönteme ait sonuçlar verilmiştir. Tablo 6'ya göre uygun gecikme uzunluğu 2 olarak belirlenmiştir. Tüm değerlerin aynı düzeyde optimum gecikme sağlaması, serilerin değişen varyans ve serisel korelasyon problemlerine sahip olmadıklar, dolayısıyla normal dağılma sahip oldukları söylenebilir. Tablo 7'de Toda-Yamamoto nedensellik test sonuçları verilmiştir.

Tablo 7. Toda-Yamamoto Nedensellik. Test Sonuclar

\begin{tabular}{|c|c|c|}
\hline Nedensellik Yönü & Test Ístatistiği & $p$ \\
\hline GSYİH $\rightarrow$ EH & 2,638 & 0,031 \\
\hline $\mathrm{EH} \rightarrow \mathrm{GSYIH}$ & 2,109 & 0,021 \\
\hline GSYİH $\rightarrow$ SH & 2,630 & 0,004 \\
\hline $\mathrm{SH} \rightarrow$ GSYİH & 2,381 & 0,001 \\
\hline GSYİH $\rightarrow$ AGH & 2,456 & 0,032 \\
\hline AGH $\rightarrow$ GSYİH & 2,514 & 0,024 \\
\hline
\end{tabular}

Tablo 7 incelendiğinde, Türkiye için GSYIHH'nın EH'ye neden olduğu $(\mathrm{p} \leq .05)$ ve EH'nin de GSYİH'ya neden olduğu görülmektedir ( $\mathrm{p} \leq .05)$. GSYİH'nın SH'ye neden olduğu ( $\mathrm{p} \leq .05)$ ve SH'nin de GSYIH'ya neden olduğu görülmektedir ( $\mathrm{p} \leq .05)$. Aynı şekilde GSYIH'nın AGH'ye neden olduğu $(\mathrm{p} \leq .05)$ ve AGH'nin de GSYIH'ya neden olduğu görülmektedir $(\mathrm{p} \leq .05)$. Böylece GSYİH ile tüm değişkenler $(\mathrm{EH}$, SH ve AGH) arasında çift yönlü bir nedensellik ilişkisi olduğu söylenebilir.

\section{Tartışma, Sonuç ve Öneriler}

Son yıllarda, ekonomi ve kalkınma politikalarına yön vermesi nedeniyle büyük bir önem atfedilen iktisadi zaman serileri arasındaki olası ilişkileri araştıran çalışmaların sayısı büyük bir artış yaşanmıştır. Zira bu seriler arasındaki ilişkilerin sağlıklı bir şekilde belirlenmesi olumlu ve daha uygun bir kalkınma stratejisi geliştirilmesine yardımcı olabilmektedir. Dolayısıyla toplumun veyahut bireylerin daha sağlıklı, bilinçli ve kaliteli yaşam standartlarına ulaşmasına yol açmaktadır. Bu amaç doğrultusunda her geçen gün yeni bir ekonomik yöntem geliştirilmektedir. Ancak iktisadi değişkenler arasındaki ilişkilerin doğru bir formda modellenmesi genellikle doğrusal olmayan yöntemlerle mümkün olabilmektedir. Bu nedenle asimetrik davranış sergilemesi beklenen iktisadi değişkenler arasındaki ilişkilerin belirlenmesinde ARDL modeli önemli bir rol üstlenmektedir. Zira eşbütünleşme testleri ile değişsenler arasındaki ilişkilerin incelenmesi için serilerin çoğunlukla aynı seviyelerde durağan hale getirilmesi gerekmektedir. Ancak serileri durağan hale getirmek için kullanılan fark alma yönteminde belirli bir oranda bilgi kaybı yaşanmakta ve bu durum sonuçların güvenilirliğini etkilemektedir. ARDL sınır testi ise farklı düzeylerde durağan olan seriler arasındaki ilişkileri ortaya çıkarabilmektedir. Böylece tüm seriler durağan hale getirilene kadar tüm serilere fark alma işlemi uygulanmasına ihtiyaç olmadığı, sadece durağan olmayan seri durağan hale getirilene kadar iteratif bir şekilde fark alma işlemi bu seriye uygulandığı için bu yöntem büyük bir avantaj sağlamaktadır.

Bu Çalışmada söz edilen gerekçeler dikkate alınarak, GSYİH'yi önemli oranda etkilediği düşünülen eğitim, sağlık ve Ar-Ge harcamalarının GSYIHH üzerindeki etkileri ARDL eşbütünleşme sınır testi ile incelenmiştir. Analiz sonuçlarına göre, \%5 anlamlılık düzeyinde Türkiye'de eğitim, sağlık ve Ar-Ge harcamaları ile GSYIH arasında uzun dönemde anlamlı ve pozitif yönlü bir ilisski olduğu söylenebilir. Ayrıca, eğitim harcamalarında meydana gelecek \%100'lük bir artışın GSYİH'da \%7,8'lik, sağlık harcamalarında meydana gelecek \%100’lük bir artışı GSYİH'da \%8,9'luk ve Ar-Ge harcamalarında meydana gelecek \%100'lük bir artışın ise GSYİH'da \%1,3'lük bir artış yaratacağı belirlenmiştir. Nedensellik test sonuçları ise GSYİH ile verilen üç değişken arasında da \%5 anlamllık düzeyinde çift yönlü nedensellik ilişkisi olduğunu göstermektedir.

Sonuç olarak, eğitim, sağlık ve Ar-Ge alanlarında yapılacak iyileştirmelerin gelir düzeyini ve dolayısıyla yaşam kalitesini artıracağı göz önüne alınarak Türkiye'de devletin bu alanlara yapacağı yatırımlar önem arz etmektedir. Bu bağlamda, ilgili kurumların politikalar geliştirilmesi önerilmektedir. 


\section{Etik Beyan}

"Ë̈itim, Sağhle ve AR-GE Harcamalar ile Ekonomik Büyüme Arasmdaki İliskinin ARDL Smer Testi ile Belirlenmesi” başlıklı çalışmanın yazım sürecinde bilimsel kurallara, etik ve alıntı kurallarına uyulmuş; toplanan veriler üzerinde herhangi bir tahrifat yapılmamış ve bu çalışma herhangi başka bir akademik yayın ortamına değerlendirme için gönderilmemiştir. Bu araştırmada hazır veri seti kullanıldığı için etik kurul kararı zorunluluğu taşımamaktadır.

\section{Kaynakça}

Akdağ, İ. (2019). Türkiye'de trafik kazaları ve ekonomik kalkınma ilişkisi: ARDL sınır testi yaklaşımı. Dicle Üniversitesi İktisadi ve İdari Bilimler Fakültesi Dergisi, 9(18), 225-248. Erişim adresi: https://dergipark.org.tr/tr/download/article-file/868604

Akıncı, A. (2017). Türkiye'de eğitim harcamalarının ekonomik büyüme üzerindeki etkisi. Maliye Dergisi, 173, 387-397. Erişim adresi: https://ms.hmb.gov.tr/uploads/2019/09/173-08.pdf

Alper, A. (2017). Türkiye'de Savunma, sağlık ve eğitim harcamalarının ekonomik büyüme üzerine etkileri. Uluslararası Ticarect ve Ekonomi Arastrmalar Dergisi, 1(2), 59-70. https://doi.org/10.30711/utead.351556

Altun, Y., İşleyen, Ş. ve Görür, C.. (2018). Türkiye'de eğitim ve sağllk harcamalarının ekonomik büyümeye etkisi: 1999-2017. Van Yǚüncü Yal Üniversitesi Sosyal Bilimler Enstitiüsü Dergisi, 39, 223-244. Erişim adresi: https://dergipark.org.tr/tr/download/article-file/666931

Baldacci, E., Clements, B., Gupta, S. ve Cui, Q. (2008). Social spending, human capital, and growth in developing countries. World Development, 36(8), 1317-1341. https://doi.org/10.1016/j.worlddev.2007.08.003

Başar, S., Künü, S. ve Bozma, G. (2016). Eğitim ve sağllk harcamalarının ekonomik büyüme üzerine etkisi: türkiye üzerine bir uygulama. Iğdlr Üniversitesi Sosyal Bilimler Dergisi, 10, 189-204. Erişim adresi: http://sosbilder.igdir.edu.tr/Makaleler/1429527102_10_Bozma_(189-204).pdf

Coşkun, H. ve Eygü, H. (2020). Ar-Ge harcamaları ve ihracat ilişkisinin incelenmesi: Türkiye Örneği. Anemon Mus Alparslan Üniversitesi Sosyal Bilimler Dergisi, 8, 233-242. Erişim adresi: https://dergipark.org.tr/en/pub/anemon/issue/58192/761623

Çalcalı, Ö. (2019). Türkiye'de kamu eğitim harcamalarının gelişimi ve OECD ülkeleri ile PISA etkinlik karşılaş̧ırması. Cankir Karatekin Üniversitesi İktisadi ve İdari Bilimler Fakültesi Dergisi, 9(2), 449-474. Erişim adresi: https://dergipark.org.tr/tr/download/article-file/907608

Demir, Y. ve Görür, Ç. (2020). OECD ülkelerine ait çeşitli enerji tüketimleri ve ekonomik büyüme arasındaki iliş̧kinin panel eşbütünleşme analizi ile incelenmesi. Ekoist: Journal of Econometrics and Statistics, 32, 15-33. https://doi.org/10.26650/ekoist.2020.32.0005

Dickey, D. A. ve Fuller, W. A. (1979). Distribution of the estimators for autoregressive time series with a unit root. Journal of the American Statistical Association, 74(366), 427-431. https://doi.org/10.1080/01621459.1979.10482531

Dickey, D. A. ve Fuller, W. A. (1981). Likelihood ratio statistics for autoregressive time series with a unit root. Econometrica, 49(4), 1057-1072. Erişim adresi: https://www.jstor.org/stable/1912517?seq=1

Engle, R. F. ve Granger, C. W. J. (1987). Co-integration and error correction: Representation, estimation, and testing. Econometrica, 55(2), 251-276. Erişim adresi: https://www.jstor.org/stable/1913236?seq=1

Erdoğan, S. ve Bozkurt, H. (2008). Türkiye'de Yaşam Beklentisi-Ekonomik Büyüme İlişkisi: ARDL Modeli ile Bir Analiz. Bilgi Ekonomisi ve Yönetimi Dergisi, III(I), 25-38. Erişim adresi: https://dergipark.org.tr/tr/download/article-file/40506

Eriçok, R. E. ve Yılancı, V. (2013). Eğitim harcamaları ve ekonomik büyüme ilişkisi: Sınır testi yaklaşımı. Bilgi Ekonomisi ve Yönetimi Dergisi, VIII(I), 87-101. Erişim adresi: https://dergipark.org.tr/tr/download/articlefile $/ 40372$

Eygü, H. ve Coşkun, H. (2020). Türkiye'de beşeri sermaye, inovasyon ve ekonomik büyüme ilişkisinin ekonometrik analizi (1995-2018). Iğder University Journal of Social Sciences, (23), 503-522. Erişim adresi: http://sosbilder.igdir.edu.tr/Makaleler/1711012370_20_Eygu_(503-522).pdf

Ghorbel, A. ve Kalai, M. (2016). Health expenditure, human capital and economic growth in Tunisia: An ARDL bounds testing approach. Journal of Business Management and Economics, 4(08), 36-45. https://doi.org/10.15520/jbme.2016.vol4.iss8.218.pp36-45

Granger, C. W. J. (1981). Some properties of time series data and their use in econometric model specification. Journal of Econometrics, 16(1), 121-130. https://doi.org/10.1016/0304-4076(81)90079-8

Gujarati, D. N. ve Porter, D. C. (2009). Basic econometrics (5th ed.). New York: McGraw-Hill/Irwin.

Ifa, A. ve Guetat, I. (2018). Does public expenditure on education promote Tunisian and Moroccan GDP per capita? ARDL approach. Journal of Finance and Data Science, 4, 234-246. https://doi.org/10.1016/j.jfds.2018.02.005

İğdeli, A. (2019). Ar-Ge ve eğitim harcamalarının ekonomik büyüme üzerindeki etkisi: Türkiye örneği. MANAS Journal of Social Studies, 8(3), 2517-2538. https://doi.org/10.33206/mjss.520848

Kepenek, Y. ve Yentürk, N. (1994). Türkiye ekonomisi (10. Baskı). İstanbul: Remzi Kitapevi. 
Kızıl, B. C. ve Ceylan, R. (2018). Sağlık harcamalarının ekonomik büyüme üzerine etkisi : Türkiye örneği. Journal of Yasar University, 13(50), 197-209. https://doi.org/10.19168/jyasar.343055

Köprücü, Y. ve Sarıtaş, T. (2017). Türkiye'de eğitim ve ekonomik büyüme: eşbütünleşme yaklaşımı. Optimum Ekonomi ve Yönetim Bilimleri Dergisi, 4(2), 77-89. https://doi.org/10.17541/optimum.292018

Kouton, J. (2018). Education Expenditure and Economic Growth: Some Empirical Evidence from Côte d'Ivoire. Journal of Economics and Sustainable Development, 9(14), 22-34. https://doi.org/10.1353/jda.0.0025

Mah, J. S. (2000). An empirical examination of the disaggregated import demand of Korea - The case of information technology products. Journal of Asian Economics, 11, 237-244. https://doi.org/10.1016/S1049-0078(00)00053-1

Meçik, O. ve Koyuncu, T. (2020). Türkiye’de göç ve ekonomik büyüme ilişkisi: Toda- Yamamoto nedensellik testi. Insan ve Toplum Bilimleri Arastirmalar Dergisi, 9(3), 2618-2635. https://doi.org/10.15869/itobiad.748770

Narayan, P. K. (2004). Fiji's Tourism Demand: The ARDL Approach to Cointegration. Tourism Economics, 10(2), 193206. https://doi.org/10.5367/000000004323142425

Narayan, P. K. ve Smyth, R. (2006). What determines migration flows from low-1ncome to high-income countries? An empirical investigation of Fiji-U.S. migration 1972-2001. Contemporary Economic Policy, 24(2), $332-342$. https://doi.org/10.1093/cep/byj019

Nasiru, I. ve Usman, H. M. (2012). Health expenditure and economic growth nexus: An ARDL approach for the case of Nigeria. JORIND, 10(3), 95-100. https://doi.org/10.22610/jebs.v3i4.277

Özcan, B. (2017). ARDL model bounds test approach: the case of Turkey (Master Thesis). Graduate School of Science and Engineering of Hacettepe University, Ankara.

Pamuk, M. ve Bektas, H. (2014). Türkiye'de Eğitim Harcamaları ve Ekonomik Büyüme Arasındaki İlişki: ARDL Sınır Testi Yaklaşımı. Siyaset, Ekonomi ve Yönetim Araştırmalar Dergisi, 2(2), 77-90. Erişim adresi: https://dergipark.org.tr/tr/download/article-file/1025019

Pata, U. K., Yurtkuran, S. ve Kalça, A. (2016). Türkiye'de Enerji Tüketimi ve Ekonomik Büyüme: ARDL Sınır Testi Yaklaşım1. Marmara Üniversitesi Iktisadi ve Idari Bilimler Dergisi, 38(2), 255-271. https://doi.org/10.14780/muiibd.281411

Pesaran, M. H. ve Shin, Y. (1999). An autoregressive distributed-lag modelling approach to cointegration analysis. Econometrics and Economic Theory in the 20th Century: The Ragnar Frisch Centennial Symposium, Strom, S. (Ed.) Cambridge University Press, 371-413. https://doi.org/10.1017/ccol521633230.011

Phillips, P. C. B. ve Perron, P. (1988). Testing for a unit root in time series regression. Biometrika, 75(2), 335-346. https://doi.org/10.1093/biomet/75.2.335

Riyath, M. I. M. (2018). Toda and Yamamoto causality test between US \$ exchange rates and stock market prices in Sri Lanka. South Asian Journal of Social Studies and Economics, 2(3), 1-9. https://doi.org/10.9734/sajsse/2018/v2i325852

Sunde, T. (2017). Education expenditure and economic growth in Mauritius: An application of the bounds testing approach. European Scientific Journal, 13(22), 70-81. https://doi.org/10.19044/esj.2017.v13n22p70

Tarı, R. ve Alabaş, M. M. (2017). The relationship between R\&D Expenditures and economic growth: The case of Turkey (1990-2014). AIB̈̈ Sosyal Bilimler Enstitüsü Dergisi, 17(2), 1-17. Erişim adresi: https://dergipark.org.tr/tr/download/article-file/528847

Toda, H. Y. ve Yamamoto, T. (1995). Statistical inference in Vector autoregressions with possibly integrated processes. Journal of Econometrics, 66, 225-250. https://doi.org/10.1016/0304-4076(94)01616-8

Uçak, S., Kuvat, Ö. ve Aytekin, A. G. (2018). Türkiye'de ARGE Harcamaları-büyüme ilişkisi: ARDL yöntemi. Manisa Celal Bayar Üniversitesi Sosyal Bilimler Dergisi, 16(2), 129-160. https://doi.org/10.18026/cbayarsos.439428

\section{EXTENDED ABSTRACT}

Mankind is in a constant effort to increase their living standards. However, it is known that efforts alone are often not enough to achieve healthier, more conscious and quality living standards, it depends on determining the relationships between economic time series in a healthy way and therefore developing a better development strategy. Therefore, investments or expenditures are made in various fields. The origins of the researches to determine the relationship between these investment or expenditure items and economic growth have a long history and the subject is constantly up-to-date. Among these expenditures, there are social needs such as education and health, which are mainly financed by the public, as well as $\mathrm{R} \& \mathrm{D}$ expenditures. The positive effect of the budget allocated for these three expenditure items on economic growth reveals the importance of these variables. For this reason, there are many studies in the literature to determine the relationship between these variables and economic growth. Some studies in this field in Turkey; Erdoğan and Bozkurt (2008), Eriçok and Yılanc1 (2013), Pamuk and Bektas (2014), Akınc1 (2017), Başar et al. (2016), Alper (2017), Köprücü and Sarıtaş (2017), Tarı and Alabaş (2017), Kızıl and Ceylan (2018), Uçak et al. (2018) and İğdeli (2019). 
In this study, in Turkey using a data set covering the years 1996-2019, the relationship between education, health and R\&D spending and economic growth has been determining with ARDL bounds test.

Whether the time series contain unit root or not was tried to be determined by ADF and PP unit root tests, and the appropriate lag length by SIC and AIC criteria. According to both ADF and PP tests; It was determined that GDP series did not contain unit root at the level in both fixed and fixed + trend models, but EEXP (Education Expenditure), HEXP (Health Expenditure) and RDEXP (Research and Development Expenditure) series contain unit root at the level. After taking the first order differences of only non-stationary series, they were analyzed again and it was determined that these variables did not contain unit root after the difference process. According to the AIC and SIC results, the appropriate delay length was determined as 2 .

The ARDL model plays an important role in determining the relationships between economic variables that are expected to exhibit asymmetrical behavior. In addition, the series used to examine the relations between co-integration tests and variables should be stabilized mostly at the same levels. However, a certain amount of information is lost in the discrimination method used to stationary the series, and this affects the reliability of the results (Demir, \& Görür, 2020, p. 24). ARDL limit test can reveal the relationships between series that are stationary at different levels. Thus, this method provides a great advantage since there is no need to apply the difference process to all series until all series are made stationary, and only the difference is applied to this series iteratively until the non-stationary series is made stationary (Mah, 2000, s. 240; Narayan, 2004, s. 204).

Results, in 5\% significance level in Turkey in the long term, education, health and R\&D expenditure shows that there is a significant and positive relationship between GDP. Among the variables given with GDP, a model is constructed in the form of GDP $=0,107+0,078 * \mathrm{EEXP}+0,089 * \mathrm{HEXP}+0,013 *$ RDEXP. Accordingly, to results, a 100\% increase in education expenditures will increase GDP by 7,8\%, a $100 \%$ increase in health expenditures will increase GDP by $8,9 \%$ and a $100 \%$ increase in R\&D expenditures will create a $1,3 \%$ increase in GDP.

After determining the lag length $(p)$ and the maximum degree of integration $d_{\text {max }}$, the VAR $\left(\operatorname{VAR}_{\left(p+d_{\text {max }}\right)}\right)$ model with the dimension $p+d_{\text {max }}$ is created and the Toda-Yamamoto causality test is applied. The causality test results show that there is a two-way causality relationship between the three variables given with GDP at the 5\% significance level.

In addition, according to the Adjusted $R^{2}$ model, approximately $73 \%$ of the variation in GDP was explained by these three variables, there was no autocorrelation according to the Breush-Godfrey LM test, there was no heteroscedasticity problem according to the ARCH test, according to the Jarque-Bera normality test the errors was determined that it was distributed normally and there was no model building error according to the Ramsey-Reset test. According to the CUSUM and CUSUMSQ graphs, it was observed that there was no structural break in the variables.

As a result, arrangements to be made in the education, health and the $\mathrm{R} \& \mathrm{D}$ area will improve income level and quality of life. Therefore, investment the government of Turkey to these areas is important. In this context, it is recommended that relevant institutions develop policies. 